\title{
Issues in the effective use of computers in introductory and advanced courses in psychology
}

\author{
N. JOHN CASTELLAN, JR. \\ Indiana University, Bloomington, Indiana
}

\begin{abstract}
The recent proliferation of time-shared terminals, computers, and instructional software is producing a dramatic change in undergraduate education in psychology. Although computers have been used for many years in research in psychology, their use as instructional alternatives only recently has been thrust upon the academic community, a development for which many faculty-even experienced computer users-are ill prepared. The use of computers and microcomputers in instruction can provide the instructor, and more importantly, the student, with an effective pedagogical tool. However, computers cannot be introduced into the curriculum in a piecemeal or haphazard fashion. In this paper, issues involved in the effective introduction and use of computers in teaching are outlined.
\end{abstract}

There are now so many computer packages available for use in instruction in psychology that a faculty member is faced with many choices. In reading the promotional literature provided by publishers and enthusiastic authors, one has the impression that it is easy to introduce computer-based instructional materials into one's classes. Most of the documentation provided with software does little to alter that perception. However, the experience of hundreds of instructors in psychology (as well as many more in other disciplines) amply demonstrates that the path to effective integration of computers into course work is strewn with traps and pitfalls for the unwary. These problems have led to frustrating experiences for faculty and students alike and, surprisingly, often have led to the elimination of instructional computing in subsequent offerings of the course.

The purpose of this paper is to discuss ways of introducing instructional computing into courses which will enhance both teaching and learning. The curricular emphasis is on introductory and advanced substantive courses. The methods to be covered include: (1) surveying available software; (2) evaluating software for its suitability to a particular course; (3) determining the resources (hardware, software, space, staff, etc.) needed to utilize instructional microcomputing; (4) modifying the course syllabus to reflect the new resources to be used; (5) monitoring microcomputer use during the course; (6) evaluating the effectiveness of the microcomputer in improving or enhancing the course; and (7) integrating software into the departmental curriculum.

Although each of these tasks is important, and I have tried to order them in a logical sequence, circumstances at individual institutions may dictate different orders and

The author's mailing address is: Department of Psychology, Indiana University, Bloomington, IN 47405. even different considerations in response to local situations.

\section{SURVEYING AVAILABLE SOFTWARE}

There are many sources for software for use in teaching in psychology. Although an instructor can write his/her own software, the experience of many teachers is that software should be written only as a last resort. If a person has had experience using software packages in courses and has evaluated their efficacy in those courses, and if the instructor has had considerable programming experience, then writing one's own courseware might be feasible. However, it is probably easier to write a generalized analysis of variance statistical package than it is to write good instructional software. Programming expertise aside, composing courseware is still difficult because one must be knowledgeable about the relevant pedagogy as well as the particular subject area. Excellent expositions of these issues may be found in Alessi (1984) and Steinberg (1984), and excellent discussions of the procedures possible for courseware development on a computer-intensive campus are available in Hewitt (1986) and Perkey (1986).

If an instructor does not write his/her software, where can other appropriate software be found? Fortunately, there is a growing collection of software that can be used productively throughout the psychology curriculum. There are three major publishers of software for use in higher education: COMPress, CONDUIT, and Life Science Associates. ${ }^{1}$ COMPress publishes courseware in many disciplines and distributes an excellent statistics package. CONDUIT is a nonprofit organization that subjects software to extensive peer evaluation, review, and testing prior to publication. It also publishes software for a number of disciplines, including psychology. Life 
Science Associates is a small company that has a library of software of special interest to behavioral scientists.

There are several other small commercial publishers. These are often enterprises set up by individuals who have written software for use in their own courses. Although some of these "one-package" companies are quite good-particularly in the area of statistical softwaresome of the others distribute slick brochures through mass mailings but deliver software that is of dubious value.

A growing source of software is the commercial book publisher. A few years ago, book publishers did not know how to market or distribute software. Today, although the situation is improving, they are still searching for the best way to distribute software and make a profit, or just break even. It should be noted that, except for introductory psychology courses and statistics courses, the curriculum in our discipline is characterized as a "thin" market. That is, it is difficult for a publisher to make a satisfactory profit because of the relatively small size of the classes and the large discretion given faculty in selecting books. If it is difficult to market books in this area, then it is equally difficult to market software.

The commercial textbook publishers market both quite expensive software and relatively inexpensive software. According to the advertising, such software often is tied to a particular textbook, or textbooks, published by the company. However, with few exceptions, most of these computer-based materials can be used in other same-level courses that use different textbooks.

Another source of information about courseware may be found in a variety of publications. Behavior Research Methods, Instruments, \& Computers (BRMIC) has published program descriptions and listings for many years. In addition, BRMIC has published papers on the pedagogy and use of computers in instruction. Contemporary Psychology is planning to publish reviews of software. Teaching of Psychology often has papers of interest in this area. In addition, there are a number of relatively new journals that publish relevant information: Computers and the Social Sciences, Computers in Human Behavior, and Collegiate Microcomputing. Even mass-market publications, such as Byte and Personal Computing, include papers and reviews of interest.

A final note on sources: There is no best source, although some are clearly better than others. As with any medium, you must know that quality cannot come cheaply. Look for materials that have been subjected to thorough and impartial peer review. However, as we shall see, even excellent material cannot be used without a serious evaluation by the teacher who will use it in his/her classes.

\section{EVALUATING SOFTWARE}

The evaluation of instructional software is perhaps one of the most critical and most difficult aspects of selecting software for use in a course. There are three essential factors: technical accuracy, pedagogical soundness, and sub- stantive fidelity. These factors are sometimes hard to judge, but an evaluation must be made if the materials are to be used effectively in instruction. I recently saw a technically brilliant program which made sophisticated use of color graphics in teaching concepts of learning that were 25 years out of date. (Most of us would not consider using a 25-year-old textbook on learning, but who would believe that one could buy microcomputer software reflecting that era? ${ }^{2}$ )

There are many useful discussions of the evaluation of instructional software (Butler \& Eamon, 1985; Castellan, 1983; Eamon \& Butler, 1985). The person interested in adopting computer-based instructional materials should review some of the relevant literature. Two recent books are of special value, particularly for those with the resources to develop their own materials (Alessi, 1984; Steinberg, 1984). Even teachers planning to utilize commercial materials will find these books of value.

\section{Technical Accuracy}

This aspect of evaluation is perhaps the most boring task to confront the reviewer. The program must be run and various alternatives taken. Does the computer have an output for every input? Does it do what the author or publisher claims? If the student types a letter (say an " $\mathrm{l}$ " for a "1"), does the program ask for corrected input, or does it simply "bomb"? Basically, does the program run without bugs? I recommend that the potential facultymember user make several passes through the program and then turn it over to student assistants who are trained to take the options systematically and copy or print the results. They will find out quickly whether the program is sound. Moreover, the data they obtain can be used later in the evaluation.

\section{Pedagogical Soundness}

This aspect of evaluation is difficult because it requires some learning of instructional technology. Most of us know little of this, even if we have been teaching for many years. What is outlined below refers to the software alone if there is no accompanying written material or to the entire package if there is software and paperwork in the form of a workbook or student guide. First, does the student understand what the program is to do and why he or she is using it? This may be simply stated as a description of what will be learned-a statement of instructional objectives. Does the program proceed in an orderly fashion in achieving these objectives? And when the program or lesson is complete, is there a restatement of the objectives? Finally, does the student know when the lesson is finished?

Throughout the sequence of the lesson, students will make errors of some sort. How are student errors handled? Must the student simply keep inputting responses, perhaps at random, until the lesson is complete? Does the software recognize errors and take appropriate action? There are many sorts of appropriate action, depending upon the material. In some cases it may be appropriate 
to return to an earlier state or stage of the lesson. In others, it may simply be enough to provide help through the use of keywords. The essential thing is that when the student has trouble, it should be dealt with in a reasonable manner, not in a way that increases the student's frustration.

It is also important that the student know how long a particular session at the terminal will take. Students do not have unlimited time, and should they try to run a 45minute program during a 30-minute period, the intent of the lesson may be thwarted. However, if a student must stop work on a lesson, is it possible to reenter at the point where he or she left or must the entire process be repeated?

Is the software designed so that it is easy to use? In most situations, we want the student to be learning content, not the technical details about the computer or the program. ${ }^{3}$ The software should be easy to use, and the concepts and terminology should be related to the material to be learned. The courseware should not compromise on the concepts to be learned, especially since we expect students to be able to apply most of them in other contexts and often in the absence of computers.

Finally, brief mention should be made of classroom use of software. In some cases it may be worthwhile to introduce the student to certain concepts by using the computer during lecture. Using a large-screen projector, it is possible to display certain functions, vary parameters, and illustrate concepts interactively (Spivey \& JacksonSmith, 1984). Consider the faculty member who comes to class with a stack of overheads illustrating some aspects of conditioning. Everything progresses well until some student asks about a schedule that is not represented by the examples. A computer simulation could be used to illustrate the concepts, and the instructor would be prepared to demonstrate even the most unusual of questions from students. Any evaluation of software should consider this possible use.

\section{Substantive Fidelity}

A program can run without error and can utilize the latest thinking concerning instructional pedagogy and still be worthless. If the content is not accurate, the material will be of little value in a course. Some materials that are peer reviewed stand a good chance of being substantively correct. But the potential user must carefully review the materials to determine that what is being taught or demonstrated is correct. This assessment requires a knowledge of the field or a willingness to spend some time reviewing the literature.

Another aspect of accuracy is the coordination of terminology between software and textbook. Unfortunately for psychologists, there is no universally accepted terminology for behavioral concepts, processes, and theories. Since there may be conflicting terminology in the sources to be used in a course, it is incumbent upon the instructor to know where these differences are and to be able to point them out, regardless of the medium in which they are found.

\section{DETERMINING THE RESOURCES}

Once one has determined that some courseware would be appropriate in a course, the matter of resources must be addressed. What resources are needed and in what quantity? If the instructor is using a departmental facility, does the use need to be coordinated with other instructors?

The effective use of courseware depends upon the provision of adequate resources to facilitate their use. Some institutions solve part of this problem by having students buy their own computers; however, at this time, most institutions still provide the hardware resources necessary for instruction. As noted earlier, we are not considering environments in which each student is expected to have a microcomputer.

\section{Hardware}

What hardware is necessary for use of particular software? Perhaps an instructor tested the material on his/her personal machine or on a colleague's while visiting at another institution. But one machine may not be enough. How much hardware is needed? It is possible to determine fairly accurately the hardware resources necessary for the use of the software by students. First, assume that the instructor wants the students to use a particular program or lesson during a 1-week period. Suppose, further, that the students have access to the computers for $8 \mathrm{~h}$ each day during the week, which yields $40 \mathrm{~h}$ available per computer. This does not translate into $40 \mathrm{~h}$ of use, since students must spend some time "setting up" to run a lesson and some time "winding down" at the end. Such time must be factored into the time allotted to each lesson or module. If each lesson takes a maximum of $30 \mathrm{~min}$, then there are 80 sessions available per computer per week. Most computing centers figure about $75 \%-80 \%$ usage of a terminal or microcomputer. This allows for down time, repair, maintenance, cleaning, and light usage during nonprime time. Thus, the terminal actually is available effectively for about $60-65 \mathrm{~h}$ per week. This calculation suggests that only one computer is necessary for a class of 50 students using the computer $1 / 2 \mathrm{~h}$ each week. But notice how this requires that the usage be spread throughout the day and week.

A better arrangement is to have several computers shared across courses. With some organization, it is possible to arrange assignments so that student work is spread across the semester. Many instructors have weeks during the semester during which no computer work is necessary. During that time, other instructors can use the computers. In the Psychology Department at Indiana University, we have a microcomputer laboratory that includes seven microcomputers for instructional work. One is reserved for system development work and printing student data. The remaining six are used throughout the semester by five to seven courses with an enrollment of 30 to 80 students each. Although a class can reserve the laboratory for a block of time, the laboratory is open to "walk-ins" during most of the day. Although we do not permit students to use the microcomputers for word 
processing, there are sufficient resources for some students to use them to run subjects for their senior theses.

Every department that utilizes computers in instruction should have a large-screen video projector for use in the classroom. Ideally, such a projector should be portable and be able to display text on a single screen in a large classroom. Although 4- to 6-ft (diagonal) projectors are not cheap, they are usually within the budget of a department or a group of departments. In order to use the video projector, one of the computers or terminals should be portable or mounted on a cart so that it can be brought easily into a classroom and used.

\section{Space}

Space for computer-based instruction need not be large, but unfortunately, many departments put their microcomputers or terminals in rooms that are little better than closets. We expect students to use the computers to enhance their learning. It is not possible to do this in space that is dirty, cramped, or noisy. A large room can be used if it is divided into cubicles similar to library carrels. Unlike computer use involving instruction in programming, computer-based learning requires attention to the task, and the environment must be conducive to study and learning. Each microcomputer or terminal should be located on a table that also provides adequate workspace for a notebook and other relevant materials to be placed open on the table and still permit the student to use the computing equipment. The ambience of the computer room should be similar to that found in the campus's library.

If at all possible, all of the computers and terminals used by a department should be placed in a single room. This will be more convenient for students, especially those who may be using computers in more than one class. In addition, it makes it easier to monitor use.

Another aspect of the computer room is that it should be relatively secure. The ideal room will not be located next to outside doors. Anyone who would attempt to remove computing equipment from the room should have to pass by several offices or classrooms. This does not prevent theft, but it does help to deter would-be thieves.

\section{Software}

There is little that can be said in general about software requirements, since they will vary with the particular materials to be used. Some facilities will be able to have the software on a hard disk which will enable students to access a single copy of the software.

In other situations, the software may be on a floppy disk. In this case, there are at least two possibilities. First, if the academic department supplies the software, there should be an adequate number of copies for several students to use them on different machines at one time. In other situations, it may be appropriate to have the students purchase the software.

Regardless of how the software is distributed or maintained, it is essential that the copyright for the particular materials be protected. Although it may seem to be attractive to make and distribute unlimited copies of the software, as noted earlier, it is important to realize that much of psychology represents a thin market, and if we want to have high-quality computer-based instructional materials, we shall have to pay for them. There are many arguments to be made concerning copying software, but until the larger issues are resolved, through appropriate laws and professional associations, I think that it is imperative that faculty take an uncompromising approach to the illegal use of computer-based materials. ${ }^{4}$

\section{Staff}

One of the most important aspects of effective computer-based instruction is adequate staff resources. As a department builds a library of software and increases its hardware resources, the staffing needs increase. Although some of this staff could be reallocated from doing different tasks, this may not fulfill the total staff requirement; the matter of staffing should therefore not be taken casually.

One of the main concerns is how to keep the equipment running. Although most microcomputers and terminals need little in the way of major repairs, routine maintenance is essential to keep the machines working well. When there are many students using the equipment, it will tend to be abused even if the students who use it are very careful. If the department has a technical or electronics support staff, many repairs can be done locally. Many schools' computing centers also have the expertise to repair and maintain equipment and often will contract to do maintenance work.

The worktables should be kept clean and free of dust, the screens on the monitors should be cleaned regularly, and keyboards and printers should be cleaned and vacuumed. These tasks could be done by a student or secretary if they have had some basic training. Disk drives must also be checked, cleaned, and recalibrated regularly. Maintenance of the disks takes more training, but often can be done by someone on the departmental staff.

Another staffing need is a computer room monitor. The function of monitor could be performed by a small cadre of undergraduate or graduate students who know what software is available, can help to maintain order in the room, help students who might have difficulty with a particular program, solve major hardware problems, and recognize minor hardware problems. If there is assistance available, students will often seek it. If no one is around, students will often persist with problems, fail to solve them, and perhaps inadvertently damage equipment. Monitors can also serve an important security function and can check out software and manuals as necessary.

Perhaps the most important staffing need is that of a faculty director. Even though many departments establish committees to determine policy and allocate resources, it is absolutely essential that some faculty member have responsibility for the facility and its overall oper- 
ation. This person would be responsible for notifying the faculty of the resources available and giving demonstrations. If problems arise with particular software, the faculty director would be responsible for overseeing the modification of the software and documentation. This important task cannot be assigned to students; someone with a long-term investment in the facility and its success is needed. Moreover, this person should have some responsibility for a budget for the facility, and should work to coordinate the activities of the departmental faculty who are using instructional computing. Finally, the departmental and campus administration should recognize that this is an essential academic function and reward it appropriately.

\section{MODIFYING THE COURSE SYLLABUS}

This is a major issue in the effective use of computers in instruction. Very little software that will teach an entire course is available. Most of it serves to support only part of a course. Many faculty are tempted simply to tell students to run certain lessons or demonstrations on the computer. This will seldom work. The instructor must make sure that the computer is used at the appropriate time in the course, must ensure that the lectures and readings are coordinated in time and content with the intended use of the computers. Examinations and other requirements must reflect the use of the computer. If the computing resources are shared with other courses, other changes in the syllabus may become necessary. This usually can be done without compromising the course or the freedom of the faculty member.

If the computer must be used outside of class time, are students made aware of this early in the course so that they can schedule their time accordingly?

What material must be added to the course and what may be deleted because of the use of the computer? This is one of the most difficult instruction problems (Castellan, 1986). Although it is obvious that material about how to use the computer would have to be added to the course, it is somtimes not recognized that consequent to the computer use, some content material might be deleted. One can easily think of how one might delete certain material from a statistics course when students use computers, but what about using computers in courses in social or cognitive psychology? This question cannot be answered here but depends upon a careful review of the syllabus.

\section{MONITORING COMPUTER USAGE}

In any course using computers, it is necessary to monitor computer usage throughout the course. Are the resources being underutilized (this might provide an opportunity for future use) or is there intense pressure on the resources so that students must work quickly and then get away from the computer so that some other student can use it? Are students sharing experiences when appropriate and not sharing them when it is not?
While the most important reason for monitoring computer use is to determine whether students are utilizing the resources effectively, another purpose would be to identify and justify the need for additional resources. One way to monitor usage is to utilize a software checkout system. When a student comes to the computer laboratory, he or she could sign out the software and note the date and time. The date and time could also be recorded when the materials were returned. Such record keeping can assist the instructor in determining usage patterns. Are some lessons taking longer than expected? Are students distributing their usage or clustering it and running several lessons at one time? Anecdotal information from students is a poor indicator about usage patterns, and only hard data should be used when making decisions concerning the use of computers in instruction.

\section{EVALUATING THE EFFECTIVENESS OF INSTRUCTIONAL MICROCOMPUTING}

Well before the course begins, the instructor should have some basic goals or expectations in mind concerning the use of the computer. In addition to these goals, the instructor should establish, in advance, some way of assessing the effectiveness of the computers in reaching these goals. Such an assessment should not determine merely whether students think the computer helped them or was fun, but should determine whether the computer did indeed have the desired effect. Moreover, the assessment procedure should ensure that sufficient information is available from the assessment for the course and syllabus to be modified as necessary. Worse than finding that the use of the computer was not especially effective is not knowing what went wrong and why.

Any assessment should be based upon instructional objectives set prior to the course. A good assessment should help the instructor to determine how to improve the course. Some faculty often wrongly assume that a weak assessment indicates that computers should not be used in that course. But think of the alternatives. Perhaps computers were not used enough. Perhaps the syllabus was not structured to make appropriate use of the instructional computing resources available. As suggested earlier, perhaps the terminology used in text, lecture, and software conflict. Unfortunately, college faculty rarely assess their courses, and when, after introducing an innovation, they finally do so, they all too frequently are willing to blame any problems encountered on the innovation. The problem may lie elsewhere. Indeed, if nothing else, the assessment of instruction, simply by virtue of being done, may be a major contribution of computer-based instruction to improving the quality of higher education.

\section{INTEGRATING COMPUTERS INTO THE DEPARTMENTAL CURRICULUM}

Thus far, I have discussed integrating the use of instructional computing into a single course. However, over the 
next few years, we will be faced with integrating computer-based instructional materials not only into single courses, but into the entire curriculum.

Within a psychology department, there are several courses in which computers may be used productively. We may be doing our students a real disservice if each faculty member independently determines how to use computers in his or her own courses while ignoring how they would be used in other courses. A simple example should suffice: Suppose a statistics instructor taught students using the BMDP statistical package. The next semester, a student from that course enrolls in an advanced laboratory course in which the instructor asks the students to use SPSS for statistical analysis. While this could certainly be done, the student would not be applying directly the skills obtained in the earlier course. Would it not be more efficient for the instructors to meet and agree upon a package to be used in the departmental courses?

Recently, I argued in favor of a vertical integration of instructional software into the curriculum (Castellan, 1984). The basic argument is that certain materials might be used repetitively in different courses. The student might use the software at an elementary level in one course and proceed to use it more thoroughly and deeply in another course. However it is accomplished, departments must work to coordinate the use of computers and instructional software throughout their curriculum.

The same argument holds for the hardware. If the student uses APPLEs in one course, IBM PCs in another, and VAX mainframes in another, we must ask whether such varied experience is really necessary and conducive to learning psychology. Perhaps such experience would be appropriate if we were training computer scientists or technicians, but is it essential to the instructional objectives of the psychology department?

\section{SUMMARY}

In this paper, it was my purpose to suggest ways to make the application of microcomputers to instruction more effective. The points outlined in this paper should improve the effectiveness of instructional computing and also enable instructors to become more efficient. If faculty are able to deliver instruction better and more efficiently, they will have more time to spend in dealing directly with students on matters of substantive interest.

\section{REFERENCES}

ALESSI, S. M. (1984). Computer based instruction: Methods and development. Englewood Cliffs, NJ: Prentice-Hall.

Butler, D. L., \& EAMON, D. B. (1985). An evaluation of statistical software for research and instruction. Behavior Research Methods, Instruments, \& Computers, 17, 352-358.

Castellan, N. J., JR. (1983). Strategies for instructional computing. Behavior Research Methods \& Instrumentation, 15, 270-279.

Castellan, N. J., JR. (1984). A model for courseware development in psychology. Behavior Research Methods, Instruments, \& Computers, 16, 165-167.

Castellan, N. J., JR. (1986). Computers and the shape of the future: Implications for teaching and learning. In R. E. Anderson (Ed.), Policy alternatives for computer use in education. New York: Association for Computing Machinery.

EAMON, D. B., \& ButLER, D. L. (1985). Instructional programs for psychology: A review and analysis. Behavior Research Methods, Instruments, \& Computers, 17, 345-351.

HewetT, T. H. (1986). When every student has a computer: A new perspective on courseware and its development. Behavior Research Methods, Instruments, \& Computers, 18, 188-195.

Perkey, M. N. (1986). The effect of a machine-rich environment on courseware development: The process and the product. Behavior Research Methods, Instruments, \& Computers, 18, 196-204.

SPIVEY, J. E., \& JACKSON-SMITH, P. (1984). The electronic chalkboard. Behavior Research Methods, Instruments, \& Computers, 16, 172-175. StEINBERg, E. R. (1984). Teaching computers to teach. Hillsdale, NJ: Erlbaum.

\section{NOTES}

1. Interested readers may write for a catalog from these firms at the following addresses: COMPress, P.O. Box 102, Wentworth, NH 03282; CONDUIT, University of Iowa, Oakdale Campus, Iowa City, IA 52244; Life Science Associates, One Fenimore Road, Bayport, NY 11705.

2. I am well aware that there are, indeed, some classic textbooks which are still of pedagogical value; however, the typical textbook of that era is hopelessly out of date.

3. I remember that after studying multiple regression in a statistics course during my undergraduate days, many of us believed that the Doolittle method (of inverting matrices) was an essential and intrinisic aspect of the statistic.

4. At my institution, the rules concerning academic honesty have recently been revised. In that revision, special cognizance was given to the theft or plagiarism of computer-based materials. The sanctions against such activities are essentially the same as those imposed against theft or plagiarism of any intellectual material. 